\title{
Abnormal vascular reflexes in Charcot-Marie-Tooth disease
}

\author{
A P B R O O K S \\ From the University Department of Human Genetics, Western General Hospital, Edinburgh
}

SUMMARY Vascular reflexes were assessed in 17 adult patients with Charcot-Marie-Tooth disease using the Valsalva manoeuvre, and the pulse rate and systolic blood pressure responses to standing. Six patients showed abnormalities consistent with an autonomic neuropathy. One patient had giant nerve fibre bundles in the myenteric plexus of bowel resected for co-existent Crohn's disease, indicating histological involvement of these autonomic neurones. Other evidence of an autonomic component to the peripheral neuropathy of Charcot-Marie-Tooth disease is reviewed.

The term Charcot-Marie-Tooth disease describes those inherited, chronic, progressive, mixed but predominantly motor, peripheral neuropathies which produce initial distal leg muscle weakness and wasting with foot deformity (often pes cavus), followed by proximal leg, hand and forearm muscle involvement. Together the several types, which are inherited by various Mendelian mechanisms, are probably the commonest of the many hereditary neuromuscular diseases presenting as the Peroneal Muscular Atrophy Syndrome.

In their original description Charcot and Marie ${ }^{1}$ commented that vasomotor abnormalities were seen, and stated that in all five patients they described "the feet and legs presented a bluish or reddish coloration with widespread mottling". The possibility that such changes indicate abnormal vascular reflexes due to an autonomic component of the Charcot-Marie-Tooth neuropathy has been the subject of this study.

The Valsalva manoeuvre is used to test vascular reflexes under autonomic nervous system control. ${ }^{2}$ Changes in heart rate during and immediately after the period of strain of the Valsalva manoeuvre form a convenient, non-invasive measure of response, as shown in studies of vascular reflexes in the autonomic neuropathy of diabetes mellitus. ${ }^{3}$ Similar measurements were made in the present investigation.

Address for reprint requests: Dr AP Brooks. The Ipswich Hospital, Anglesea Road Wing, Ipswich, IP1 3PY.

Accepted 3 January 1980

\section{Patients and methods}

Seventeen aduit patients age range 20 to 71 years with Charcot-Marie-Tooth neuropathy were investigated.

The procedure used to perform the Valsalva manoeuvre described by Levin ${ }^{4}$ was adopted. After a training period the subject rested with the thorax at 45 degrees to the horizontal. Heart rate was recorded on a continuous strip of Standard Lead 1 of the ECG. The subject rapidly blew up a sphygmomanometer column of mercury to $40 \mathrm{~mm}$ for precisely 10 seconds, the period of strain, then "let go" by dropping the mouth piece immediately, heart rate being recorded for a further 15 seconds.

The Valsalva ratio (VR) was calculated from the slowest bradycardia, being the longest single $R-R$ interval in the 15 second period after strain, divided by the shortest $R-R$ interval in the 10 second period of strain. Levin found the lowest VR of 200 normal adults to be 1.38 , with $96 \%$ having a value of 1.50 or higher. Among 20 normal adult controls seen in the present study the lowest VR was $1 \cdot 50$.

A clinical assessment of circulatory response to posture change also was made. Radial pulse rate and blood pressure in the right arm were recorded when resting supine, and 30 seconds after standing; standing initiates compensatory circulatory mechanisms that are most active in the first 30 to 60 seconds after posture change. ${ }^{5}$ 
Table Valsalva ratio and pulse rate and systolic blood pressure changes in response to standing in 17 cases of Charcot-Marie-Tooth disease.

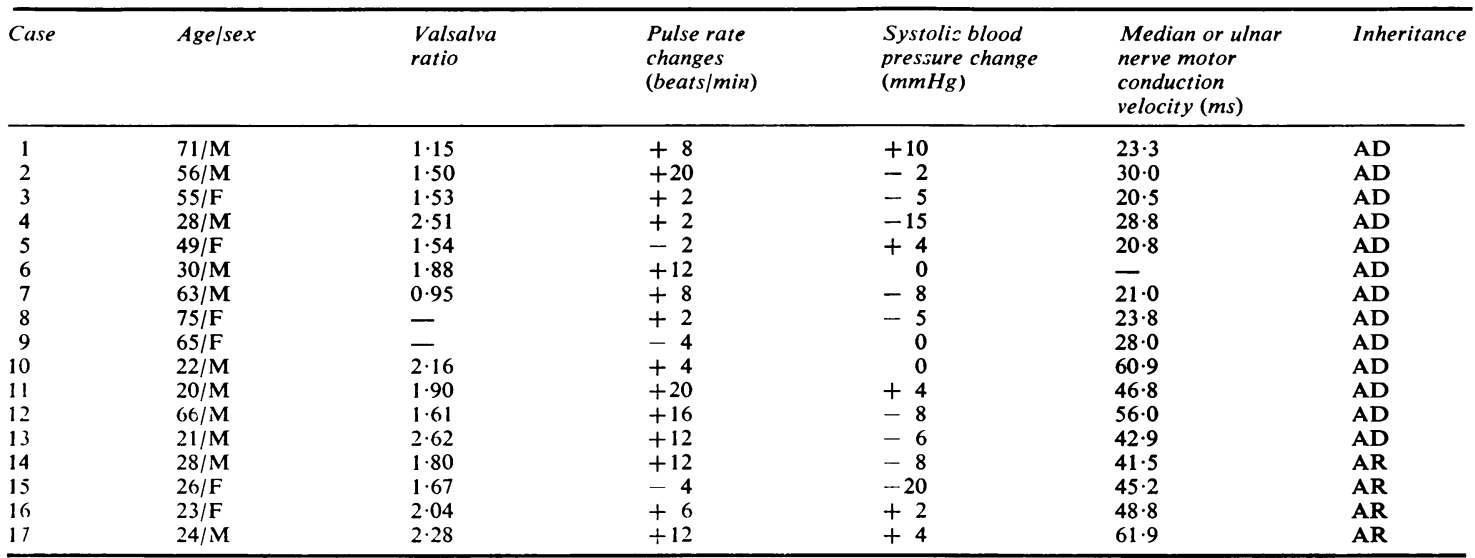

Maximum motor nerve conduction velocity: Median nerve (mean \pm 2 S.Ds $)=69 \cdot 3-49 \cdot 7 \mathrm{~ms}$. Ulnar nerve $(\mathrm{mean} \pm 2 \mathrm{~S} . \mathrm{Ds})=72 \cdot 0-51 \cdot 6 \mathrm{~ms}$. Valsalva ratio: Normal $>1 \cdot 50$.

Change in pulse rate on standing: 50 controls, age $20-54$ years, range -4 to +32 beats/min, 12 controls, age $61-76$ years, range +4 to +18 beats/ min.

Change in systolic blood pressure on standing: 50 controls, age $20-54$ years, range -14 to $+18 \mathrm{mmHg}, 12$ controls, age $61-76$ years, range -32 to $+4 \mathrm{mmHg}$.

Inheritance: AD indicates autosomal dominant; AR indicates autosomal recessive.

\section{Results}

The values for the Valsalva ratios, and the pulse rate and systolic blood pressure changes in response to standing, obtained in the 17 patients are shown in the table.

Cases 1 and 7 had frankly abnormal VRs ( 1.15 and 0.95 ). Three others, cases 2,3 and 5 , had VRs at the lower limit of normal.

Cases 8 and 9 had pulse rate changes on standing less than those of their age matched controls $(+2$ and -4 beats per minute against a control range of +4 to +18 beats per minute).

Cases 4 and 15 had systolic blood pressure falls on standing of 15 and $20 \mathrm{mmHg}$, whereas in an age matched control group the range of systolic blood pressure change was from -14 to + $18 \mathrm{mmHg}$.

\section{Discussion}

These observations indicate there is an autonomal component affecting vascular reflexes in the Charcot-Marie-Tooth neuropathies of some patients.

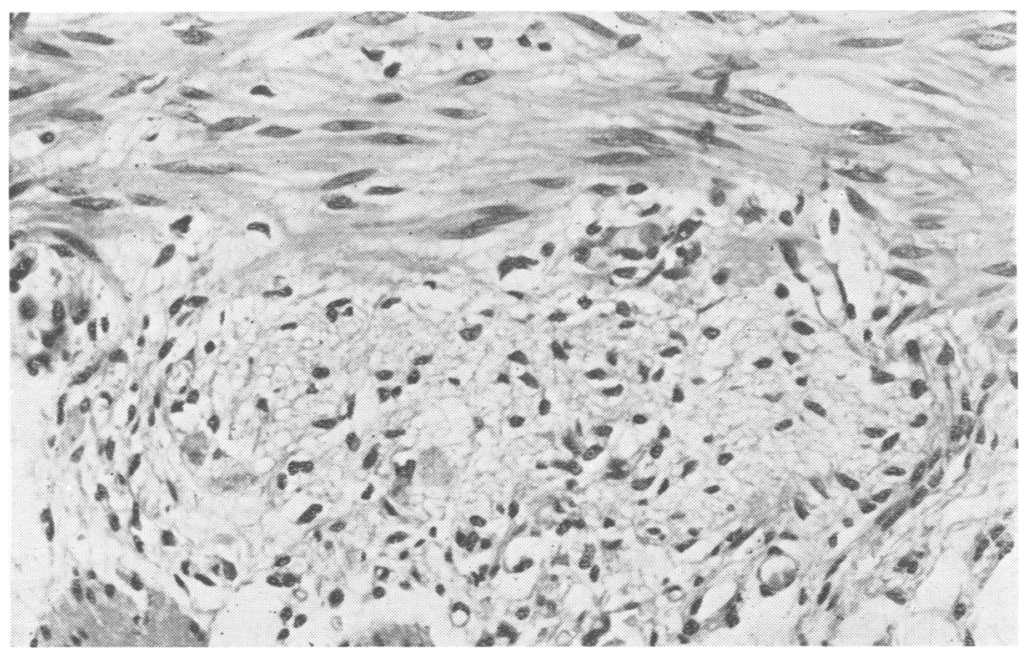

Figure Giant nerve fibre bundles in myenteric plexus of small bowel wall of case 7 . Haematoxylin and eosin $\times 400$. 
Two types of Charcot-Marie-Tooth disease inherited as an autosomal dominant trait have been described. In one type ${ }^{6}$ the peripheral neuropathy has a demyelinating or hypertrophic pathology, and maximum motor nerve conduction velocity is much delayed. Cases 1 to 9 correspond to this type, and five had evidence of abnormal vascular reflexes and vasomotor changes in their legs. Cases 10 to 13 were in the second type described ${ }^{7}$, where the peripheral neuropathy has a neuronal pathology and maximum motor nerve conduction is normal or little delayed. In the present study none of these cases had abnormal vascular reflexes.

Case 15 , who probably had an autosomal recessive neuronal type of the disease, had pronounced vasomotor changes in her legs. Her main complaint was of swollen, livid, cold legs and feet when standing. She showed severe leg muscle weakness and wasting.

Case 7 is of particular interest. He was a 63 year old man with the autosomal dominant demyelinating type of the disease and also Crohn's disease, for which he earlier had a resection of part of the ileum, caecum, and ascending colon. Histological examination revealed giant nerve fibre bundles in the myenteric plexus of the bowel wall uninvolved by Crohn's disease (see figure). In the context of Charcot-Marie-Tooth disease these appearances demonstrated histological proof of autonomic nervous system involvement. Similar myenteric plexus nerve fibre changes have been recorded in the Riley-Day syndrome of familial dysautonomia. ${ }^{8}$

There are other reports of autonomic nervous system involvement in Charcot-Marie-Tooth disease. Jammes ${ }^{9}$ showed four patients to have abnormalities of skin temperature regulation, circulatory reflexes as measured by changes in blood pressure and pulse rate with posture, impaired sweating in the legs, low tear production, and small pupils with no dilatation under dim light. These abnormalities were ascribed to involvement of post-ganglionic sympathetic fibres.

In a detailed ophthalmological study, ${ }^{10} 13$ of 15 affected individuals in a large family with autosomal dominant Charcot-Marie-Tooth disease had pupillary abnormalities resembling those in the Holmes-Adie syndrome, indicating parasympathetic denervation of the iris sphincter and ciliary muscle.

Biochemical studies ${ }^{11}$ suggest that less than normal of the enzyme dopamine- $\beta$-hydroxylase, which catalyses the final stage in the synthesis of noradrenaline, flows down the sural nerve axons of patients with peripheral neuropathies including
Charcot-Marie-Tooth disease.

The abnormal vascular reflexes demonstrated in the present study may be explained by loss of postganglionic sympathetic fibres in addition to disease of the peripheral motor and sensory fibres in Charcot-Marie-Tooth disease. The additional finding of histological abnormality of the myenteric plexus in one case, and the observations of others, suggest that autonomic neuropathy may be widespread.

This work was carried out while a Medical Research Council Training Fellow under the supervision of Professor AEH Emery in the University Department of Human Genetics, Western General Hospital, Edinburgh.

\section{References}

1 Charcot, J-M, et Marie, P. Sur une forme particulière d'atrophie musculaire progressive souvent familiale débutant par les pieds et les jambes et atteignant plus tard les mains. Rev Med, 1886; 6:97-138.

2 Spalding, JMK. The autonomic nervous system and the circulation. Proc $R$ Soc Med, 1966; 59: 461-3.

3 Ewing DJ, Campbell IW, Burt AA, Clarke BF. Vascular reflexes in diabetic autonomic neuropathy. Lancet, 1973; 2:1354-6.

4 Levin AB. A simple test of cardiac function based upon the heart rate changes induced by the Valsalva maneuver. Am J Cardiol, 1966; 18:90-9.

5 Wald H, Guernsey M, Scott FH. Some effects of alteration of posture on arterial blood pressure. Am Heart J, 1937; 14:319-30.

6 Dyck PJ, Lambert EH. Lower motor and primary sensory neuron diseases with peroneal muscular atrophy. I. Neurologic, genetic and electrophysiologic findings in hereditary polyneuropathies. Arch Neurol, 1968; 18:603-18.

7 Dyck PJ, Lambert EH. Lower motor and primary sensory neuron diseases with peroneal muscular atrophy. II. Neurologic, genetic and electrophysiologic findings in various neuronal degenerations. Arch Neurol, 1968; 18:619-25.

8 Solitare GB, Cohen ES. Peripheral autonomic nervous system lesions in congenital or familial dysautonomia. Neurology, 1965; 15:321-7.

9 Jammes JL. The autonomic nervous system in peroneal muscular atrophy. Arch Neurol, 1972; 27:213-20.

10 Keltner JL, Swisher CN, Gay AJ, Hepler RS. Myotonic pupils in Charcot-Marie-Tooth disease. Successful relief of symptoms with $0.025 \%$ pilocarpine. Arch Ophthalmol, 1975; 93:1141-8.

11 Brimijoin S, Capek P, Dyck PJ. Axonal transport of dopamine- $\beta$-hydroxylase by human sural nerves in vitro. Science, $1973 ; 180: 1295-7$. 